Managementforschung 3 



\section{Managementforschung 3}

Herausgegeben von

Wolfgang H. Staehle und Jörg Sydow

\begin{tabular}{|c|}
$\mathrm{W}$ \\
$\mathrm{DE}$ \\
$\mathrm{G}$
\end{tabular}

Walter de Gruyter · Berlin · New York 1993 
Prof. Dr. Wolfgang H. Staehle $\dagger$, Institut für Management, Freie

Universität Berlin, Garystr. 21, 1000 Berlin 33

Prof. Dr. Jörg Sydow, FB Wirtschaftswissenschaft, Bergische Universität Wuppertal, Gaußstr. 20, 5600 Wuppertal 1

Das Buch enthält 22 Abbildungen und 4 Tabellen

(2) Gedruckt auf säurefreiem Papier, das die US-ANSI-Norm über

Haltbarkeit erfüllt

Die Deutsche Bibliothek - CIP-Einheitsaufnahme

Managementforschung / Berlin ; New York : de Gruyter. - 23cm

Erscheint jährlich. - Aufnahme nach 1 (1991)

$1(1991)$

ISBN 3-11-013644-9

(c) Copyright 1993 by Walter de Gruyter \& Co., D-10785 Berlin.

Dieses Werk einschließlich aller seiner Teile ist urheberrechtlich geschützt. Jede Verwertung außerhalb der engen Grenzen des Urhebergesetzes ist ohne Zustimmung des Verlages unzulässig und strafbar. Das gilt insbesondere für Vervielfältigungen, Übersetzungen, Mikroverfilmungen und die Einspeicherung und Verarbeitung in elektronischen Systemen.

Printed in Germany.

Datenkonvertierung durch: Knipp Satz und Bild digital, Dortmund. - Druck: Gerike GmbH, Berlin. - Buchbinderische Verarbeitung: Dieter Mikolai, Berlin. - Umschlagentwurf: Johannes Rother, Berlin. 